\title{
Living Lab - An Open and Citizen-Centric Approach for Innovation
}

\author{
Birgitta Bergvall-Kåreborn and Anna Ståhlbröst \\ Social Informatics \\ Luleå University of Technology \\ SE-97187 Luleå, Sweden \\ Fax: +46920492849 \\ E-mail: Birgitta.Bergvall-Kareborn@1tu.se \\ E-mail: Anna.Stahlbrost@ltu.se
}

\begin{abstract}
In this paper we focus on a new research area, Living Lab that introduces new ways of managing innovation processes. A Living Lab can be viewed as both an innovation milieu and an innovation approach, and the aim of this paper is to clarify these two perspectives, as well as to illustrate how they can enrich each other. This is done by presenting one Living Lab milieu, Botnia Living Lab, and its key components; and one Living Lab approach, FormIT, and its key principles. The presentation is done on two levels, one general level and one case specific level. The case focuses on involving citizens in the design of an e-service aimed to increase their influence in a municipality and its development. Through this we learnt that the key components of a Living Lab constitutes important structures that enhance the process and as such the principles.
\end{abstract}

Keywords: Living Labs, citizen-centric, FormIT, design, innovation, openness, realism, empowerment of users

Biographical notes: Birgitta Bergvall-Kåreborn is an Associates professor in Social Informatics at Luleå University of Technology, where she also earned her Ph.D. Her current research interests concern participatory design in distributed and open environments; human centric and appreciative methodologies and methods for design, evaluation and learning; and, the relation between IT-use and IT-design. She has contributed to the field of participatory design with more than thirty conference- and journal publications, and served as a referee in a number of academic conferences and journals.

Anna Ståhlbröst is a researcher and project manager at Luleå University of Technology, Sweden. Her research interests are process-based methods, which include various stakeholders, to appreciate opportunities for innovative technology development in Living Lab environments. These methods specifically focus on generating user needs from different real-world use situations and assessing users' experience of specific IT artefacts. Anna's research objective is to contribute to the design process to assure that innovative technologies will represent user needs and thereby give the users an added value. Anna has participated in several international and national innovation projects and her research is related to Botnia Living Lab and to establishing networks of Living Labs, both on European and Nordic levels. 


\section{B. Bergvall-Kåreborn, A. Ståhlbröst}

\section{Introduction}

Living Lab has become an umbrella concept for a diverse set of innovation milieus emerging all over Europe. Even though they differ in many ways, both in focus and approach, there also are a few common denominators pulling them together (Shami 2008).

In order to join forces, coordinate activities, and share learning experiences, a European Network of Living Labs has developed. The aim of the network is to offer a gradually growing set of networked services to support the "Innovation Lifecycle" for all actors in the system: end-users, SMEs, corporations, the public sector, and academia. Today, the network consists of 51 Living Labs, and in the end of 2008 a third recruitment wave started.

The definition of Living Lab given by the network is that "a Living Lab is an open innovation environment in real-life settings in which user-driven innovation is the cocreation process for new services, products, and societal infrastructures. Living Labs encompass societal and technological dimensions simultaneously in a business-citizensgovernment-academia partnership."

The rationale behind these new milieus, to open company boundaries toward their environment and to harvest creative ideas and work capabilities existing among different stakeholder, is similar in its approach to other open methodologies, e.g., open innovation (Chesbrough 2003; Chesbrough and Appleyard 2007), crowdsourcing (Brandel 2008; Hempel 2007), and involving lead users (Von Hippel 1986; Von Hippel and Katz 2002). Living Labs also share many characteristics with user-centred approaches such as "participatory design" and "socio-technical design" (Bekker and Long 2000).

In this paper, we will focus on Living Labs aimed to create a shared arena in which digital services, processes, and new ways of working can be developed and tested with user representatives and researchers.

Since Living Labs is a rather new research area, the amount of supporting theories for understanding the concept is limited (Feurstein et al. 2008). The same is true when it comes to methodologies, methods, and tools. Here, there is a lack of systematic analyses and reflection on available methods and tools and their suitability to the Living Lab context (Følstad 2008). Thus, Feurstein et al. (2008) argue for a structuring of the approaches used in Living Labs in order to gain an overview of what is used and to what extent.

In this paper, we take a different approach by focusing on one Living Lab milieu, Botnia Living Lab, and one Living Lab approach, FormIT (Bergvall-Kåreborn, Holst, and Ståhlbröst 2008; Ståhlbröst and Bergvall-Kåreborn 2008) and reflecting on their strengths and weaknesses in relation to given Living Lab components and principles. The aim of the paper is to clarify these two perspectives, and to illustrate how they can enrich each other. By this, we participate in the building of a common knowledge base of existing practice that later can be accessed.

In the following, we present the concept of Living Lab and its key components and principles. Subsequently, we introduce Botnia Living Lab, followed by FormIT. Thereafter, a description of our research method and a case that illustrates the milieu and the approach is given. After this we reflect on the key principles and key components, as well as the relation between. Finally, the paper ends with some final remarks.

\section{Living Labs}

Living Lab started to emerge in the beginning of 2000 (Markopoulos and Rauterberg 2000), with an initial focus on testing new technologies in home-like constructed 
environments. Since then, the concept has grown; today, one precondition in Living Lab activities is that they are situated in a real-world context.

During the design of the concept, Living Labs has been defined as an environment (Ballon, Pierson, and Delaere 2005; Schaffers et al. 2007), as a methodology (Eriksson, Niitamo, and Kulkki 2005) and as a system (CoreLabs. 2007). We do not see these three definitions as contradictory but rather as complementary perspectives. Depending on which perspective one takes, certain themes come into focus. With the environment perspective, objects such as technological platforms and user communities come to the forefront. With the methodology perspective, it is processes such as data transfers and methods for user involvement that are highlighted.

In this paper, we focus on both the environmental and methodological perspective of Living Labs, since these are the most common views. One way of illustrating a Living Lab environment can be seen in Figure 1. The figure outlines the key components of a Living Lab. Users represent end-users, or potential end-users as the innovation co-creators and valuators. Application environments represent the context in which those users interact and reflect the real world's usage scenarios. The technology and infrastructure component outlines the role that new and existing ICT technology can play to facilitate new ways of cooperating and co-creating innovations among the partners and stakeholders. Organisation and methods relate to proposed standards and methods that emerge as best practice within the Living Labs environment. Finally, the Living Labs partners bring their own specific wealth of knowledge and expertise to the collective, helping to achieve higher standards of excellence of every area.

Figure 1: Key Components of a Living Lab

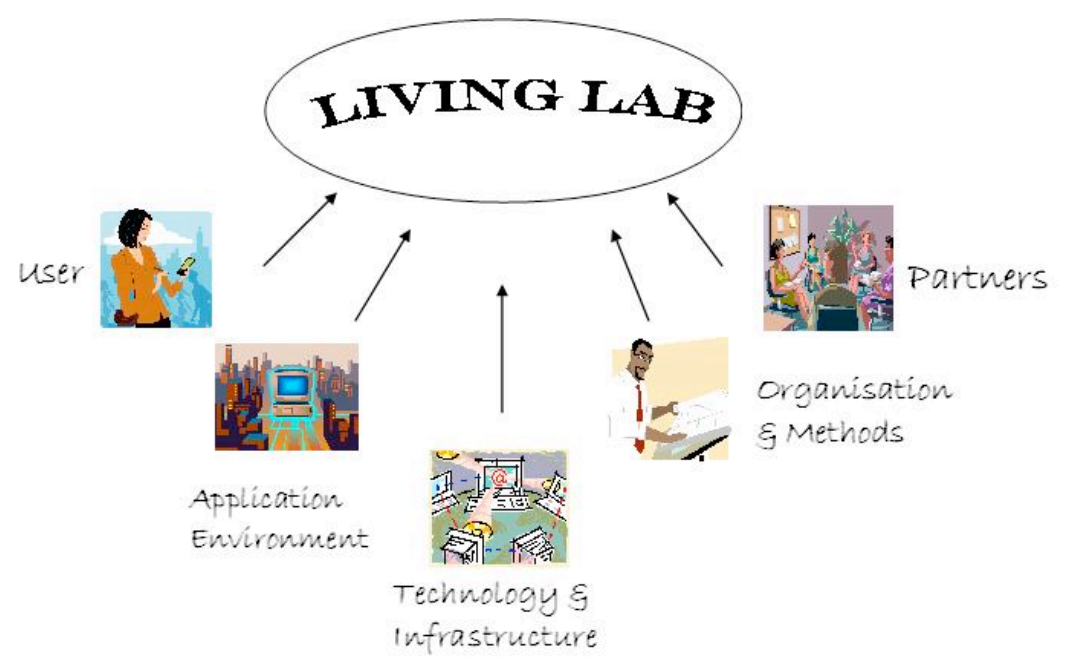

In relation to the Living Lab methodology five key principles have been suggested (CoreLabs. 2007):

- Continuity: This principle is important since good cross-border collaboration, which strengthens creativity and innovation, builds on trust, which takes time to develop.

- Openness: The innovation process should be as open as possible since gathering of many perspectives and bringing enough power to achieve rapid progress is important. 


\section{B. Bergvall-Kåreborn, A. Ståhlbröst}

The open process also makes its possible to support the process of user-driven innovation, including users wherever and whoever they are.

- Realism: To generate results that are valid for real markets, it is necessary to facilitate as realistic use situations and behavior as possible. This principle also is relevant since focusing on real users, in real-life situations, is what distinguishes Living Labs from other kinds of open co-creation environments, such as Second Life.

- Empowerment of users: The engagement of users is fundamental in order to bring innovation processes in a desired direction, based on humans' needs and desires. Living Labs efficiency is based on the creative power of user communities; hence, it becomes important to motivate and empower the users to engage in these processes.

- Spontaneity: In order to succeed with new innovations, it is important to inspire usage, meet personal desires, and fit and contribute to societal and social needs. Here, it becomes important to have the ability to detect, aggregate, and analyse spontaneous users' reactions and ideas over time.

Among these five principles, three stands out, as they represent the core of Living Labs. The first is empowerment of users, since the main role of Living Labs is "to engage and empower users to participate in the generation of valuable and sustainable assets toward objectives set up by its partners and customers" (CoreLabs. 2007, p. 9). This relates strongly to user-centric approaches of different types, such as "participatory design" and "socio-technical design" (Bekker and Long 2000).

The second is openness, which can be related to open innovation (Chesbrough 2003; Chesbrough and Appleyard 2007), crowdsourcing (Brandel 2008; Hempel 2007), and involving lead users (Von Hippel 1986; Von Hippel and Katz 2002). The third is realism and focus on real-world settings. This principle also is the most distinguishing characteristic of a Living Labs compared to both open approaches and user-centric approaches. Due to this, we will focus on these three principles in this paper.

\section{Botnia Living Labs}

The Living Lab described in this paper is called Botnia; it focuses on developing innovative IT services or products, with real users, from the basis of user needs, in a realworld context. This Living Lab is open for all kinds of IT stakeholders and aims to facilitate the collaboration process between all relevant stakeholders in the value-chain, and to help these stakeholders manage their innovation processes with users. During its life cycle, the aim of Botnia has altered. In the beginning, the main objective was to facilitate user tests of innovations for SMEs and researchers. This focus has matured and increased, and today Botnia not only performs user tests, but also aims to support processes in which users are involved as equal co-creators of innovations in close cooperation with companies, users, academia, and authorities.

In this cooperation, a few stable partners have been crucial for the sustainability of the Living Lab, especially in the start-up phase. Two very important contributors to the environment are Ericsson and TeliaSonera. Besides these large telecommunication companies, there also are a number of small and medium-sized companies that have followed and contributed to the development of Botnia. On the public side, there is a close relationship between Botnia and researchers in diverse sciences. Each science, as well as each partner, contributes in its specific knowledge area. Besides these more stable partners, there are many companies and public authorities that are more loosely coupled to the Lab. They might participate in a project and then cease the relation to Botnia when the project ends. 


\section{Living Lab - An Open and Citizen-Centric Approach for Innovation}

Over the years, Botnia has built up a community of end-users with which they easily can communicate; hence, they are the centre of the organisation. This community includes 5,800 test pilots who have, as private persons, voluntarily chosen to be part of the Living Lab community. One unifying factor among these test pilots is their curiosity to try new technical artefacts and to get the opportunity to influence them. What separates them are demographical and psychosocial factors (Ståhlbröst 2004). The blend of people available through this community makes it possible to select and tailor a test target group in relation to the needs and wants of the test initiator. Here, the test initiator can be represented by customers buying a user test or the test initiator can come from within the Living Lab organization. The only requirement test pilots must meet is to have access to a mobile phone.

Since Botnia aims to involve real-world users in real-world use situations throughout the innovation process, each study becomes customised in accordance with the unique requirements for that particular study. The contexts for each individual study can differ substantially, from reindeer herders in rural areas to city residents in traffic jams, even though the focus of Botnia always is to develop innovative IT services or products.

The technology and infrastructure platforms are available through the Living Lab collaboration partners. This platform, with its Living Lab portal, constitutes the focal point of the Living Lab since this is where projects are presented to the end-users and where end-users are recruited. The portal also is where the interaction between end-users and other partners takes place. In order to extend the number of users a Living Lab can access there are a number of EU-funded research projects that aim to connect different platforms together in order to widen the scope of the activities that can be carried out.

As with the technological platform and infrastructure, there is a need to learn more about the methodologies, methods, and tools that are used in Living Lab situations, and also to reflect on their suitability. There is no lack of existing methodologies, methods, and tools used in individual Living Labs, but there are few studies that reflect on the methods used in relation to the unique character of Living Labs. There also is a need to develop new methodologies, methods, and tools specific to the aim and context of Living Lab, especially new distributed methods for user involvement, since users are involved in the development process independent of their location. One such methodology, developed based on the practice within Botnia, will be presented in the next chapter.

Another important aspect of Botnia's methodological and organisational structure is the "living" aspect. This means that the people involved in any development project "live" with the process and constantly check how the process proceeds, thus being prepared for any necessary adjustments to ensure, for example, that users are stimulated to participate, or that the development process proceeds as planned. If the process does not proceed as planned, the aim is to gather data about what has happened and how the plans can be adjusted accordingly. The Living Lab organisation in which we are involved is based on the development project that currently is running; hence, the project's aim and process highly influence the Living Labs activities, participants, and structure. This can mean, for example, that if a certain competence is missing in the organisation, SMEs can be involved to fill that spot. Finally, the Living Lab setting also enables sharing experiences across partners as well as for research. Botnia aims to harmonise the development process and the innovations, among four main stakeholders; companies, users, authorities, and researchers. The close relationship between research and development is one important characteristic.

\section{FormIT - an Illustration of a Living Lab Methodology}




\section{B. Bergvall-Kåreborn, A. Ståhlbröst}

In this section, we present the framework of ideas and characteristics of FormIT before we introduce the general shape of FormIT, in order to give a holistic view of the methodology. The kernel of this paper is concept design, and this part of FormIT therefore will be presented in more detail through an illustration of a case later in this paper.

\subsection{Framework of Ideas}

FormIT is inspired by three theoretical streams: Soft Systems Thinking (SST), Appreciative Inquiry (AI), and NeedFinding (NF). From the first stream, Soft Systems Thinking (Checkland 1981; Checkland, Forbes, and Martin 1990; Checkland and Holwell 1998), the assumption that changes can occur only through changes in mental models is utilised. This implies that we need to understand both our own as well as other stakeholders' worldviews, and we need to be clear about our interpretations and the base on which they are made. The second stream, Appreciative Inquiry (Cooperrider and Avital 2004; Cooperrider and Whitney 2005; Cooperrider, Whitney, and Stavros 2005; Norum 2001), has encouraged us to start the development cycle by identifying different stakeholders' dreams and visions of how IT can improve and support the lives of people. This includes a focus on opportunities, related to specific trends, contexts, or user groups, and on the positive and life-generating experiences of people (Holst and Ståhlbröst 2006; Ståhlbröst and Holst 2006).

This way of thinking is closely aligned with the philosophy behind SST, since it also highlights the importance of people's thoughts about themselves and the world around them in a design situation. Hence, instead of starting the process by searching for problems to solve in a situation, we identify what works well and use this as a basis for design.

The third stream, NeedFinding, has two different inspirational sources. The NeedFinding concept, as such, and its motivation finds its origin in a paper by Patnaik and Becker (1999). Patnaik and Becker argue that the main motivators for the NeedFinding approach are that needs are not influenced highly by trends; hence, they are more long lasting. The needs generation process, on the other hand, is inspired by Kankainen and Oulasvirta (2003) and Tiitta (2003). These authors inspire us to focus on user needs throughout the development process, and to use these as a foundation for the requirement specification.

Figure 2. The FormIT Process for Systems Development 


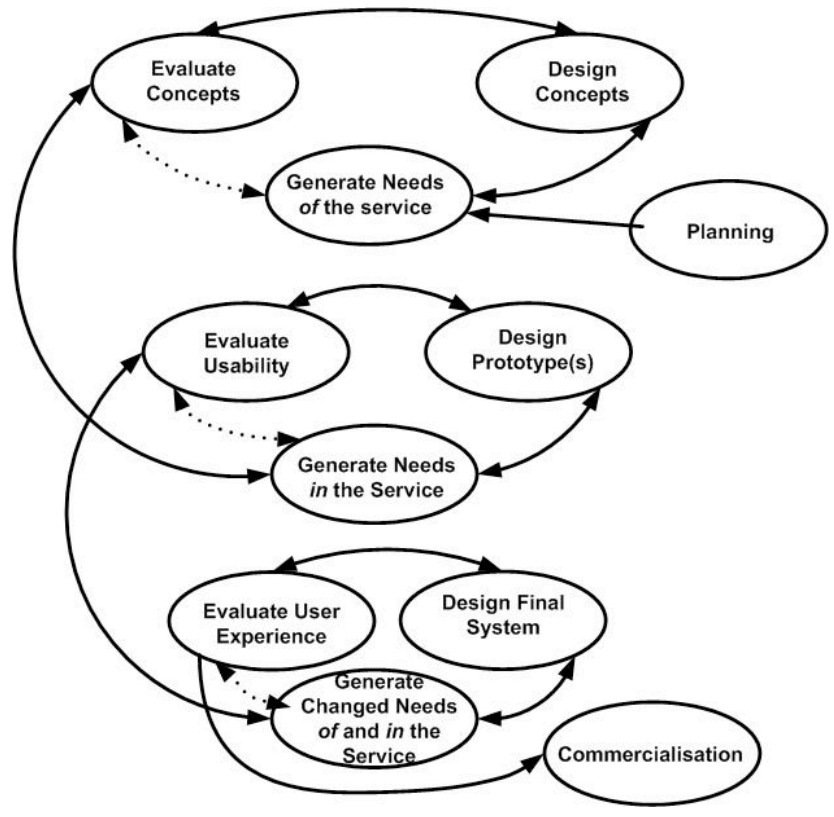

\subsection{Characteristics of FormIT}

Grounded in these three theoretical streams, FormIT enables a focus on possibilities and strengths in the situation under study; this is fundamentally different from traditional problem-solving approaches. In our perspective, identifying opportunities is the basis for appreciating needs since needs are opportunities waiting to be exploited (Holst and Ståhlbröst 2006; Ståhlbröst and Holst 2006). Hence, FormIT strongly stresses the importance of the first phase in the concept design cycle, usually referred to as analyses or requirements engineering. Since this phase creates the foundation for the rest of the process, errors here becomes very hard and expensive to correct in later stages. This also is the phase in which users can make the strongest contributions, by actually setting the direction for the design rather than mainly responding to (half finished) prototypes. Since users' needs and requirements can change as users gain more knowledge and insights into possible solutions, it is important to continually reexamine their needs and make sure they correlate to given requirements.

In accordance, the FormIT method is iterative, and interaction with users is an understood prerequisite. The idea is that knowledge increases through iterative interactions between phases and people with diverse competences and perspectives (Holst and Mirijamdotter 2006; Mirijamdotter, Somerville, and Holst 2006). In this way, knowledge increases through dialogue among participants. The idea is that the cross-functional interaction enables the processes of taking knowledge from one field to another to gain fresh insights, which then facilitates innovative ideas. The shared understanding of the situation informs and enriches the learning processes and thus facilitates changes in perspective and leads toward innovative design-processes. This, in turn, increases our qualifications to design IT systems that answer to user needs (Ståhlbröst and Holst 2006).

\subsection{General shape of FormIT}


The FormIT process can be seen as a spiral in which the focus and shape of the design becomes clearer, while the attention of the evaluation broadens from a focus on concepts and usability aspects to a holistic view on the use of the system; see figure 2 .

In this process three phases - Generate Needs, Design, and Evaluate - are repeated in three iterative cycles. The first cycle is called Concept Design, the second Prototype Design, and the third Final System Design. The name of the cycle indicates the expected output of each cycle. Besides these three cycles, two additional phases are included in the figure. The first is planning, seen in the upper right hand corner of the figure, and the second is commercialisation. The focus of this paper is concept design, which is managed in the first cycle, illustrated in the upper level of figure 2 .

\section{Research Method}

In this study, we have chosen an action research approach. Action research means that one enters a real-world situation with the aim of both improving it and creating knowledge (Baskerville and Wood-Harper 1998; Checkland and Holwell 1998). It is an established method within social sciences, including information systems (Baskerville and WoodHarper 1996; Jönsson 1991), and is thought to produce highly relevant results because it is grounded in practical action and aims to solve immediate problem situations while informing theory. Baskerville and Wood-Harper (1996) even argue that "action research is one of the few valid research approaches that researchers can legitimately employ to study the effects of specific alterations in systems development methodologies" (p. 240).

Action research also is a methodology well suited for Living Lab since both approaches emphasise interaction between theory and practice, involve many different stakeholders with distinct roles relevant in the situation, and highlight the importance of constant reflection in order to follow wherever the situation leads.

Focusing on both the practical and the theoretical in a situation, and how they enrich each other, fits well with the dual role we have had in this study. Our project role and responsibility were to appreciate technological opportunities that could improve citizens' possibilities and willingness to participate in municipality development. Our research aim was to develop FormIT further through reflection on our experiences of applying the methodology in this particular situation. This also meant that we gained knowledge on how a Living Lab milieu and a Living Lab approach can enrich each other.

The key components of a Living Lab can be found on two different levels. One describes the general framework of a Living Lab, while the other describes separate projects carried out within the general framework. While the first level brings stability and continuity to the lab, the second facilitates spontaneity and represents the living aspect of a lab. To illustrate this, we have separated the two levels into the Botnia Living Lab and the SMART case. Since the data gathering in the case is mainly a part of the aim of improving the situation it will be integrated and reported in the Case section.

\section{Case}

The background to the SMART case was a general feeling that citizens lack opportunities to communicate easily with public authorities. This results in few citizen-driven suggestions and opinions for how the municipality should develop. To facilitate active participation among citizens, the project aimed to develop IT services that increased citizens' abilities to influence and improve the society. 
Living Lab - An Open and Citizen-Centric Approach for Innovation

The SMART project had three different but intertwined purposes:

- to give product and service developers the opportunity to engage citizens and user groups in their change, quality, and innovation processes

- to give citizens and individuals the opportunity to engage in these innovation processes

- to create opportunities for a dynamic region where boundary-crossing cooperation becomes usual in the change processes on all levels from product development to community building.

The project was carried out in an interactive manner in cooperation among citizens, companies, and authorities. Here, this meant local universities, municipalities, and private SME companies, as well as citizens. All of these partners brought valuable knowledge and expertise into the project. The universities brought knowledge about user-centric methods for design; the municipalities contributed with the situation as such, and with visions on how they would like the interaction with citizens to be; the SMEs brought the technical know-how to the project; and the citizens contributed their stories about how they interacted with public authorities today and how they would like to interact.

The citizens' participating in the project was heterogeneous in character, with a blend of ages, gender, civil status, and occupation. The citizens were between 18-50 years old, and there were 11 men and 13 women. The participants were selected from the Living Lab community based on where they lived, their age, gender, and occupation. The aim of the heterogeneous group was that, to some extent, they should represent a broad range of citizens. Diverse groups also have the benefit of generating mixed perspectives that challenge the statue quo and presents alternative ways of viewing situations.

The technology should facilitate the possibility for citizens to interact and communicate with public authorities when a need occurred, independent of time or space. Based on this, it was decided to explore and develop the concept of "reaction media." It also was decided that the service should be able to run on both mobile and stationary devices.

To gain understanding of the potential users and their situations, focus group interviews were used as the main data-collection method. In this study, five focus group interviews, each with four to six citizens, were carried out, as well as one individual interview. These focus group interviews lasted between one to two hours. The focus of the interviews was to discuss citizen's experiences and thoughts related to communication with municipalities and governments.

The stimulus material we used in these focus groups was scenarios related to communication with authorities, alarm, and suggestions for improvement of society. Whenever the focus group discussion stopped, we introduced a new theme or question.

From the user stories, needs were generated and translated into requirements for designing the prototype. It is the design team's role to develop concepts, mock-ups, or prototypes that incorporate the needs of the users. This does not mean that users cannot participate in this work; it is meant as a clarification of the different knowledge assets held by different roles and where their responsibilities lie (Bergvall-Kåreborn, Holst, and Ståhlbröst 2008).

In this project, no evaluation of the prototype took place, since we were unable to recruit the necessary number of users to conduct a relevant test; this was despite a number of recruitment activities. We decided not to recruit citizens from the Living Lab community since these people have a bias toward technology-interested people, early adopters, and a willingness to influence situations. They also had participated in questionnaires and focus group interviews in the beginning of the project, and we wanted 


\section{B. Bergvall-Kåreborn, A. Ståhlbröst}

people who were new to the project and its ideas. Therefore, we advertised for test people in the local newspapers three times, but despite this repeated effort we only managed to recruit about ten people. Therefore, we decided not to have a regular evaluation; instead, we did an internal test within the project.

The result of the project was a well functioning prototype for a system in which citizens could enter a Web portal and give suggestions for improvements or alert hazardous situations. The portal could be entered either via mobile phones or PCs. However, it never was implemented at the municipalities. The reasons for this never were investigated. But, a simpler version of the concept was developed and implemented about a year later. Even though this might not be seen as a success story, it is our experience that it represents quite a standard illustration of many development projects. Studies indicate that only 15 percent of companies' development time is invested in products that reach the market (Feurstein et al. 2008).

\section{Reflecting on Key Principles}

In this section, we discuss and reflect on how the Living Lab principles relates to key components in the SMART case.

\subsection{Openness}

The principle of openness emphasises that the innovation process should be as open as possible. The idea is that multiple perspectives bring power to the development process and achieve rapid progress. The openness supports the process of user-driven innovation.

In the SMART project, many different stakeholders participated and each had an agenda and perspective. The weakest link in the partnership was the municipalities. Though they were positive about the project and its endeavour, they did not participate operationally in the project. This can be one important reason why the system never was implemented into their organisation. Hence, the SMART project points to the importance to have both strategic and operational commitment among key stakeholders.

In relation to the last part of the principle, that inclusion of many different stakeholder perspectives supports the process of user-driven innovation, we want to offer a world of warning. It is important to recognise that inclusion of multiple stakeholders does not guarantee a user-driven innovation process.

A lesson learnt from the SMART project, as well as from earlier projects, is that openness is easier said than done. This is true on many different levels. Firstly, the evaluation phase in our project clearly illustrated that citizens do not join automatically just because we want them to or ask them to do so. This always has been the case, but in voluntary use situations it becomes even more noticeable. In work settings, participating in development projects often is part of the work role, but no such driving force exists in relation to systems developed for private use.

When it comes to actually listening to the citizens and taking their ideas into consideration, the project managed very well, and most of the generated needs were included in the final design of the system. This can be related both to an openness in the design team for this way of working and to the nature of FormIT. FormIT's framework of ideas strengthens this way of working-AI, through its appreciative nature, SST though its focus on diverse perspectives as a way to challenge present frames of thought, and needfinding, with its focus on understanding users and their needs. The openness principle therefore is related closely to the empowerment principle, as we will indicate when we discuss this principle. 
Living Lab - An Open and Citizen-Centric Approach for Innovation

\subsection{Realism}

Realism is one of the principles that clearly separates Living Lab from traditional systems development as well as other kinds of open co-creation environments, such as Second Life. The principle highlights the necessity to facilitate realistic use situations and behaviour as much as possible in order to generate results that are valid for real markets.

Understanding the citizens and their interaction with public authorities was difficult, since there was no clear and limited application environment. It would have been possible to observe them in their real-world environment but, considering the limited amount of interaction that most people have with public authorities, this would have required long observation cycles and very patient citizens. An alternative would have been to focus on people visiting public authorities, but this would generate understanding only of single and isolated encounters, and we wanted a systemic view of people's relationship with these authorities. Hence, we carried out our appreciative user study in traditional ways: meeting for focus group interviews in easily accessible locations.

To set them in a real-world mode, we presented a number of scenarios and asked the focus groups to relate to these and reflect on how they thought they would behave in similar situations.

Another important aspects related to realism, but not specifically addressed by the principle is the fact that different stakeholders view reality different. This also is one often mentioned reason why it is crucial to involve users as well as many different stakeholders in the development process. Instead of trying to understand someone, we should let people participate and tell their own stories, and learn form this.

\subsection{Empowerment of users}

The key element in the empowerment principle is to base innovations on humans' needs and desires, and to utilise the creative power of user communities.

Empowerment of users also is a key characteristic in FormIT, and it is visible in many different ways. Firstly, users and other stakeholders are seen as partners in the innovation process, not just as co-designers, which is common in most systems development projects. Inherent in being a partner, from an end-user perspective, is the power of choice. People always can choose if, when, and to what extent they want to participate.

Secondly, including potential end-users guarantees participation and facilitates involvement. However, in our view, influence is the key to empowerment, that is, if user needs and ideas can be traceable in the concepts, prototype, and finished product. FormIT's iterative process between phases and between cycles makes it possible for users to judge whether their participation and involvement contributed to and influenced key deliverables.

As was said in relation to openness, the citizens had influence over the final system. Their needs and suggestions were taken seriously and implemented as functions and features in the prototypes and final system. However, as is often the case, they had influence because the partners kept open minds and wanted to base the solution on real user needs rather than on their own predetermined views of what citizens like.

The technical system as such also aimed to empower citizens by giving them the possibility to influence their municipality. But, when we look at the system that actually was implemented, this system was less empowering. Here, the citizens were not able to give suggestions about what they prioritised as important; instead, the system only allowed input on issues that the municipality selected as important to get feedback on. Hence, it is 


\section{B. Bergvall-Kåreborn, A. Ståhlbröst}

important to have an open discussion with all stakeholders on what empowerment represents. Is it the freedom to set a boundary or to give comments within an already defined boundary. Our view is that empowerment requires the possibility to set boundaries.

\section{Reflecting on Key Components}

In this section we alter the perspective and reflect on how the key components express themselves in practice. Starting with the user, we found that the user community is one crucial asset and that it is important that these communities represent the mixture that reflects the surrounding society. However, these user communities have a tendency to be biased toward technically mature and curious people who like to have influence on societal changes. In the SMART study, we acknowledged the biased population and aimed to recruit users who were not involved actively in the community. However, we found it difficult to recruit users who did not have biases, since these are personal characteristics that make them eager to contribute to these processes.

When it comes to application environment, it was rather difficult to carry out appreciative user studies in a real-world setting since the situation we aimed to study was a relatively small and seldom occurring part of the citizens everyday life. In the project we were, therefore, not able to carry out the need generation phase in the real-world situation of the citizens. Instead, we facilitated discussions focused on their interaction and reflection on their real world experience related to the SMART-application. This indicates the need for mobile tools that empower the citizens and give them the opportunity to express their thoughts, experiences, and ideas regardless of where and when they arise.

In relation to technology and infrastructure we have found that technological support constitutes one focal point for user interaction in Living Labs. In Botnia, the user community is one important place where potential users can be accessed easily. However, having a large user community also includes the necessity to create enough activities to keep the users active and motivated to participate, yet at the same time not overload them. From an empowerment perspective, the user community is more geared toward information to users. Further, communication and interaction is initiated from Botnia and its needs rather than from the user community and its needs. Hence, to facilitate empowerment for the users, a more balanced relationship needs to be established. To make this community even more heterogeneous, it is important to create cooperation between individual Living Labs in the European Network of Living Labs (ENOLL).

The organisation and method of a Living Lab environment represent the proposed standards and methods that emerge as best practice within the Living Lab environment. As such it is correlates to the applied Living Lab approach. However, depending on the nature of the remaining Living Lab components, the practice of the key principles of the Living Lab approach will differ. For example, empowerment of users or openness is always important but they can take many different forms. In our study we used the FormIT methodology and found that it harmonized well with the basic idea of Living Labs. It is open and facilitates empowerment of users. However, its week point is in relation to realism. Here we find that there still is much work to be done before the process actually meets the vision of truly taking place in the users' real-world contexts throughout the whole innovation process, as well as being truly user-driven.

Looking at the partnership in a Living Lab we have found that it is important to have a mixture of large, medium, and small organisations as well as long and short term partnerships. As with the user community, diversity in the kind of partners that contribute 


\section{Living Lab - An Open and Citizen-Centric Approach for Innovation}

to the Living Lab is positive from a development and innovation perspective since they can bring different opportunities, resources, and, experiences to the collaboration.

\section{Final Remarks}

In this paper, we have presented a Living Lab environment called Botnia and a methodology called FormIT. We have reflected on how they correspond to key components and principles of Living Labs and how these components and principles can enrich each other.

Among the three principles, we find that it is within realism that we often lack the knowledge and experience to truly interact in the user's real-world environment throughout the whole development process. Considering that this principle also is the principle that distinguishes Living Labs from other open and user-centred approaches, it is important to gather more knowledge in this area. It also is important to gain deeper understanding of the relationship between the three principles of openness, empowerment, and realism in order to understand how they can strengthen each other in future development projects.

In relation to the key components, we found that it is difficult to recruit user groups that reflect the variety of the society, since participating in the development of new technology attracts people with certain personal characteristics. Regarding the three components application environment, technology and infrastructure, and, organisation and methods we observe that it is the principle of realism that is hardest to achieve. One reason for this can be the shift in design context that is taking place, which result in a lack of methods and tools that can support these new design contexts. When it comes to the partnership of a Living Lab it is important to have a mixture of stable and flexible partnerships, since the stable give continuity to the Lab while the more flexible partners contribute new perspectives and ideas.

Finally, based on the above discussion and final remarks we conclude that the key components of a Living Lab constitutes important structures that enhance the process and as such the key principles.

\section{References}

Ballon, P., J. Pierson, and S. Delaere. (2005). Open Innovation Platforms For Broadband Services: Benchmarking European Practices. in 16th European Regional Conference, at Porto, Portugal.

Baskerville, R L., and A T. Wood-Harper. (1998). Diversity in Information Systems Action Research Methods. European Journal of Information Systems 7:90-107.

Baskerville, Richard L., and Trevor A T. Wood-Harper. (1996). A Critical Perspective on Action Research as a Method for Information Systems Research. Journal of Information Technology 11:235-246.

Bekker, Mathilde., and John. Long. (2000). User Involvement in the Design of HumanComputer Interactions: Some Similarities and Differences between Design Approaches. In People and Computers XiV: Proceedings of the HCI 2000, edited by S. McDonald and G. Cockton. Springer: New York. 135-147.

Bergvall-Kåreborn, B., M. Holst, and A. Ståhlbröst. (2008). Creating a New Leverage Point for Information Systems Development. In Designing Information and Organizations with a Positive Lens, edited by M. Avital, R. Boland and D. Cooperrider. Elsevier Science /JAI Press Oxford. 75-95.

Brandel, Mary. (2008). CROWD SOURCING: Are You Ready to Ask the World for Answers? Computerworld 42 (10):24-26.

Checkland, P. B. . (1981). Systems Thinking, Systems Practice. John Wiley \& Sons: Chichester. 


\section{B. Bergvall-Kåreborn, A. Ståhlbröst}

Checkland, P.B, P Forbes, and S Martin. (1990). Techniques in Soft Systems Practice Part 3: Monitoring and Control in Conceptual Models and in Evaluation Studies. Journal of Applied Systems Analysis 17:29-37.

Checkland, Peter B., and Sue. Holwell. (1998). Action Research: Its Nature and Validity. Systemic Practice and Action Research 11 (1):9-21.

Chesbrough, H. (2003). Open Innovation: The New Imperative for Creating and Profiting from Technology. Harvard Business School Press: Cambridge, MA.

Chesbrough, Henry., and Melissa. Appleyard. (2007). Open Innovation and Strategy. California Management Review 50 (1):57-76.

Cooperrider, D L., and Michel. Avital, eds. (2004). Advances in Appreciative Inquiry, Constructive Discourse and Human Organisation. Vol. 1. Elsevier: Oxford.

Cooperrider, D L., and Diana. Whitney. (2005). Appreciative Inquiry - A Positive Revolution in Change. Berrett-Koehler Publishers: San Francisco.

Cooperrider, D L., Diana. Whitney, and Jacqueline M. Stavros. (2005). Appreciative Inquiry Handbook. Berrett-Koehler Publishers: San Francisco.

CoreLabs. (2007). Living Labs Roadmap 2007-2010: Recommendations on Networked Systems for Open User-Driven Research, Development and Innovation. In Open Document. Luleå: Luleå University of Technology, Centrum for Distance Spanning Technology.

Eriksson, M., V.P. Niitamo, and S. Kulkki. (2005). State-of-the-art in Utilizing Living Labs Approach to User-centric ICT innovation - a European approach: Centre of Distance Spanning Technology at Luleå University of Technology, Sweden, Nokia Oy, Centre for Knowledge and Innovation Research at Helsinki School of Economics, Finland.

Feurstein, K., A. Hesmer, K A. Hribernik, K D. Thoben, and J. Schumacher. (2008). Living Labs: A New Development Strategy. In European Living Labs - A New Approach for Human Centric Regional Innovation, edited by J. Schumacher and V. P. Niitamo. Wissenschaftlicher Verlag: Berlin. 1-14.

Følstad, A. (2008). Living Labs for Innovation and Development of Information and Communication Technology: A Literature Review. The Electronic Journal for Virtual Organisations and Networks 10 ((Special Issue on Living Labs)):100131.

Hempel, Jessi. (2007). Tapping the Wisdom of the Crowd. Business Week Online:27.

Holst, M., and A. Mirijamdotter. (2006). Framing Multi-Disciplinary Teams: Sense Making Through the POM-model. 12th Annual CPTS Working Conference Integrating Visions of Technology, edited by A. Basden, A. Mirijamdotter and S. Strijbos. 25-28 April, at Maarssen, The Netherlands. 111-131.

Holst, M., and A. Ståhlbröst. (2006). Enriching the Process of Appreciating Needs with Storytelling. International Journal of Technology, Knowledge and Society. Vol. 2 (4):61-68.

Jönsson, Sten. (1991). Action Research. In Information Systems Research: Contemporary Approaches and Emergent Traditions, edited by H.-E. Nissen, H. K. Klein and R. Hirschheim. North-Holland: Amsterdam. 371-396.

Kankainen, A., and A. Oulasvirta. (2003). Design Ideas for Everyday Mobile and Ubiquitous Computing Based on Qualitative User Data. User Interface for All, LNCS 2615, edited by N. Carbonell and Stephanidis, at Berlin. 458-464.

Markopoulos, P., and G W M. Rauterberg. (2000). Living Lab: A White Paper. In IPO Annual Progress Report.

Mirijamdotter, A., M. M. Somerville, and M. Holst. (2006). An Interactive and Iterative Evaluation Approach for Creating Collaborative Learning Environments. The Electronic Journal of Information Systems Evaluation (EJISE) 9 (2):83-92. 
Living Lab - An Open and Citizen-Centric Approach for Innovation

Norum, Karen E. (2001). Appreciative Design. Systems Research and Behavioral Science 18:323-333.

Patnaik, Dev., and Robert. Becker. (1999). Needfinding: The Why and How of Uncovering People's Needs. Design Management Journal 10 (2):37-43.

Schaffers, H, M Cordoba, P Hongistro, T Kallai, C Merz, and J Rensburg. (2007). Exploring Busniess Models for Open Innovation in Rural Living Labs. In Proceedings of the 13th International Conference on Concurrent Enterprising. Sophia-Antipolis, France.

Shami, Tayyab Abbas. (2008). Living Labs: Good Practices in Europe. In European Living Labs - A New Approach for Human Centric Regional Innovation, edited by J. Schumacher and V. P. Niitamo. Wissenschaftlicher Verlag: Berlin. 15-30.

Ståhlbröst, A. (2004). Exploring the Testbed Field. 27th Information Systems Research Seminars in Scandinavia, IRIS 27, at Falkenberg, Sweden.

Ståhlbröst, A., and B. Bergvall-Kåreborn. (2008). FormIT - An Approach to User Involvement. In European Living Labs-A New Approach for Human Centric Regional Innovation, edited by J. Schumacher and V. P. Niitamo. Wissenschaftlicher Verlag: Berlin. 63-76.

Ståhlbröst, A., and M. Holst. (2006). Appreciating Needs for Innovative IT Design. International Journal of Knowledge, Culture and Change Management Vol. 6.

Tiitta, S. (2003). Identifying elderly people's needs for communication and mobility. Include 2003 March.

Von Hippel, E. (1986). Lead User: A Source of Novel Product Concepts. Management Science 32 (7):791-805.

Von Hippel, Eric., and Ralph. Katz. (2002). Shifting Innovation to Users via Toolkits. Management Science 48 (7):821-833. 